\title{
perifèria
}

Número 10, Junio 2009

www. periferia.name

\section{I maginación y reacción en los Campamentos de refugiados saharauis: construcción de la cotidianeidad e identidad frente al otro extranjero (nasrani) en el contexto de la diáspora}

\author{
David de Juan Canales, Universidad Autónoma de Madrid ${ }^{1}$
}

\begin{abstract}
Resumen
Los Campamentos de refugiados son una parte dramática de la historia del pueblo saharaui con poca referencia bibliográfica. Esta situación ha impuesto una serie de límites ante los cuales la imaginación de la sociedad civil ha reaccionado y ha generado un espacio alternativo donde vivir. La revolución contra el colonialismo es además una lucha por cambiar el propio pasado y algunos hábitos culturales. Y desde el refugio y el exilio se han abierto nuevas alternativas que ha aprovechado la educación como pilar fundamental de la revolución. Desde ella se prepara a las nuevas generaciones para la libertad y a través de ella se recupera y enseña la identidad nacional saharaui. Este trabajo muestra la labor y las dificultades que rodean al mundo de la educación en el refugio y la importancia que tiene la memoria histórica.
\end{abstract}

Palabras clave: campamentos de refugiados, saharauis, revolución, educación, identidad.

\begin{abstract}
Saharawi refugee camps, with little references, are part of the recent tragic history. This situation has imposed a series of limits to which the imagination of civil society has reacted and has generated an alternative space in which to live. The revolution against colonialism was also a struggle to change the past and some cultural habits. And the refuge and the exile have opened new alternatives which have taken education as a fundamental pillar of the revolution. Since it prepares future generations for freedom and through it to recover and teach the Saharawi national identity. This paper shows the work and the difficulties surrounding the world of education at the shelter and the importance of historical memory.
\end{abstract}

Keywords: refugee camps, sahrawi, revolution, education, identity.

\footnotetext{
${ }^{1}$ Enviar correspondencia a: David de Juan Canales (david_dejuan@hotmail.com)
} 


\section{perifèria}

Número 10, Junio 2009

\section{www. periferia. name}

La identidad saharaui se ha ido construyendo en torno a discursos históricos y textos etnográficos recogidos en los periodos pre-colonial, colonial y del refugio tanto por los extranjeros o nasrani ${ }^{2}$ en sus estudios científicos como por los propios saharauis a través de la tradición oral y algunos manuscritos. La identidad saharaui adquiere interés con motivo de la situación política de olvido y manipulación en la se encuentra el proceso de descolonización, y que ha tenido como principal resultado la diáspora y el exilio del pueblo saharaui, además de la creación de Campamentos de refugiados, que se han terminado convirtiendo en población permanente al cabo de los años, a pesar de las recomendaciones de los organismos internacionales y de los derechos humanos. El conflicto ha transformado la identidad y la sociedad saharaui, pasando a ser una realidad rota y múltiple que se ve influenciada también por el contacto con otros pueblos. Esta situación provoca que la población sufra física y moralmente el olvido, la apatía, la agonía y la ausencia de alternativas de futuro: "el vacío del alma no se cubre solo teniendo el estómago lleno".

Ante esta situación de impotencia queda al menos el derecho a reivindicar su especificidad histórica y cultural, y adecuarla al modelo de "Estado-Nación" (D.Smith 2000:97-100) moderno como una estrategia tan legítima como lo ha sido para el resto de Estados. Para ello es necesario recuperar la memoria histórica y cultural antes de que quede en el olvido, teniendo en cuenta el sesgo que introducen la invención y la imaginación, así como procesos de "aculturación" (Bonelli, 1944) o la influencia de otras culturas en este mundo globalizado. Así también conseguiremos evitar tergiversaciones y fraudes de la historia. Paralelamente, el pueblo saharaui lleva a cabo un proceso de adecuación de valores del pasado a los procesos de justicia social, igualdad de género y libertad.

La Poesía (Baroja 1990: 393-438), de tradición oral, símbolo de la “ausencia de peso" en la cultura nómada, ha mantenido la función transmisora de la historia, del amor, de la patria y de los lamentos, incorporando en ocasiones la música. La

2 Ser árabe y musulmán es un hecho identitario diferencial respecto al hecho de ser yahudi (judío) o nasrani. Nasrani significa extranjero en referencia a los habitantes de Nazaret o amigos de Jesús Cristo y a aquellos que le ayudaron, mientras que en árabe significa solo cristiano y para los saharauis cristiano y extranjero, sin tener por ello un sentido peyorativo. Ser saharaui también lleva implícitos una serie de rasgos culturales específicos. 


\section{perifèria}

Número 10, Junio 2009

www. periferia. name

oralidad como legado corre el riesgo de perderse debido a la avanzada edad de quienes la poseen. Hoy día son los jóvenes el eslabón generacional con el conocimiento y la enseñanza de la poesía, igual de infiel que la historiografía árabe respecto a los hechos por su artificiosidad y fantasía ${ }^{3}$, pero que podemos apoyar con los testimonios e historias. Es en definitiva una recuperación de lo tribal que en ocasiones responde a intereses reaccionarios, no como un intento de recuperar y entender el pasado, sino como una forma de establecer diferencias y límites. Sin embargo, al mismo tiempo ocurre lo contrario, se suman las poesías que introducen los jóvenes retornados de países cultural e ideológicamente distintos, de manera que la poesía sigue siendo un elemento cultural intergeneracional que mantiene el respeto entre jóvenes y adultos y que se ha adaptado a las nuevas circunstancias y que nos ofrece una imagen dinámica de la historia.

No vamos a caer en el error del esencialismo y otorgar a la circunstancialidad de los hechos un valor universal. La historia es una forma más de explicar los acontecimientos que a veces permite justificar el derecho de algunos grupos a organizarse y distinguirse libremente, como en este caso, del extranjero o nasrani. Cuando los árabes emigraron hacia el África occidental desde la península del Yemen (primera diáspora) se mezclan con los pueblos que allí habitaban, principalmente beréberes, lo que supone el nacimiento de tribus mixtas que se fueron diferenciando gradualmente en el tiempo y en el espacio, y configurando una nueva comunidad nómada o beidani (Hernández 1989:64-74), antes de llegar a llamarse saharauis, argelinos, marroquíes o mauritanos. En aquella zona del Bidán se fue construyendo una identidad cultural propia. Una nueva fase de contacto entre culturas definidas en tribus ${ }^{4}$ aparece gracias al comercio con el actual Marruecos, Mauritania y Senegal en las rutas de caravanas que describe Ibn Jaldún, y que se ve potenciada por el comercio con los españoles durante la época de la colonización. La causa de su sedentarización en los años 50 y 60 del siglo XX se debió a una gran sequía que les obligó a dejar su modo de vida nómada y aceptar las condiciones de un trabajo obrero a las órdenes de los empresarios, a vivir en ciudades industriales con una estructura social diferente de la que existía

\footnotetext{
${ }^{3}$ Corán XXVI: 227,228.

${ }^{4}$ Ibíd. XLIX: 11-14.
} 


\section{perifèria}

Número 10, Junio 2009

\section{www. periferia. name}

en las ciudades árabes y de actividad fundamentalmente comercial. Palabras del poeta Ruygal Berig en este período colonial español se han transmitido oralmente y han definido este periodo como: "se fue esta religión a otro camino perdido en el olvido y el pueblo hizo como que es un desayuno, almuerzo y comida". Aquella adaptación a lo nasrani no anula el deseo de recuperar modos de vida de antaño, su trabajo y el lugar donde vivieron. Es a partir de esta idea de pertenencia a un territorio y a una cultura, lo que en los años 70 favorece el surgimiento de movimientos de liberación en todo el mundo entre los universitarios sometidos al poder colonial, como sucedió en Marruecos y como sucede en el Sáhara Occidental. En este caso, surge desde el Frente Polisario y en la figura de Mohamed Sidbrahim Bachir. Su objetivo principal es crear un nuevo sistema social basado en tesis marxistas y socialistas con el fin de eliminar de la práctica social el tribalismo y cualquier tipo de discriminación, puesto que como dijo Luali Mustafá Sayed (19471976) en los primeros años de la revolución "el tribalismo es una bomba debajo de nuestros pies", y supone un peligro para la creación de un Estado libre, igualitario y democrático, como así se expresa en su Constitución. Fueron hechos como la Asociación de jaimas en 1967 lo que inició una nueva mentalidad: "cada uno venía de una tribu y una tierra, pero ahí se unían como saharauis". Entre los años (Criado 1977: 365-479) del inicio de la organización de los Campamentos (1977) y el alto el fuego (1991), las relaciones de género y de poder han sufrido las mayores transformaciones, los hombres se van a la guerra ${ }^{5}$ y las mujeres se quedan a cargo

\footnotetext{
${ }^{5}$ Durante la guerra existía un código social, los Principios de la Revolución, que permitió durante los años de guerra y posteriores la supervivencia del pueblo saharaui.

1- La violencia como defensa justificada (al unf azzauri).

2- El sacrificio por la patria (attadhiya).

3- La disciplina y el orden (al iltizam).

4- El secretismo (asserriya).

5- La crítica y autocrítica (annagd wa annagd addati).

6- El análisis de los sucesos y acontecimientos de manera subjetiva (attahlil el elmi).

7- Aprovechar el tiempo y los logros de la revolución (al mohafada ala al wakt wa ala makasib azzaura).

8- Igualdad democrática -entre sexos, razas y tribus- (almusawat addimukratiya).

9- Transparencia y sinceridad democrática (assaraha azzauriya).

10- Creer en uno mismo y en el pueblo (azzikatu binnafsi wa bi achchaab).

11- Saber defenderse sólo contando con tu propia fuerza (al iitimad ala annafs).

12- Servir de ejemplo para los demás (almizaliya).

13- Continuidad (al istimrariya).
} 


\section{perifèria}

Número 10, Junio 2009

www.periferia. name

como administradoras de los Campamentos (Juliano 1999: 83-87), los jóvenes toman decisiones y los ancianos las respetan.

La globalización conciencia a la sociedad civil saharaui de un mayor protagonismo y participación, reclama valores universales que incorporen sin exclusión a todos los sectores de la sociedad, aunque aún quedan reminiscencias del sistema de relaciones y de poder tribal, del que reniegan principalmente las nuevas generaciones que han emigrado. Hoy en día, el conocimiento de otras concepciones de vida que muestra la televisión o los nasrani, genera nuevas alternativas y valores, lo que modifica aspectos culturales como el casamiento, la familia o el trabajo, el amor o la amistad.

Actualmente la movilidad social es más frecuente. Antes las tareas o hábitos de un grupo estaban más marcados, hábitos o actitudes frente a la religión, la vestimenta, la posición tribal, el género, etc. y ello requería practicar diferentes estrategias para poder acceder a otros espacios, como el público o el privado, siendo este el de la familia, eje en el funcionamiento y la estructura social. Sin embargo, lo tribal y lo religioso se someten a la imaginación social e individual, a la utilización de estrategias que permiten generar nuevas relaciones y modelos sociales, alternativas en definitiva, que a menudo se invisibilizan en base a las relaciones de poder (Contreras 1991:343-359).

A partir de todos estos valores compartidos, que no han evitado empero las desigualdades sociales y las distintas maneras de acceder a los recursos, se ha generado una nueva ideología nacionalista de lucha y de pertenencia. Lo tribal se difumina y pasa a tener un papel más relevante la familia y el hecho de poder extender las relaciones familiares y de amistad, como muestra el modo en que las remesas de dinero, las jubilaciones, las familias españolas o los fondos de cooperación mantienen a muchas de esas familias y "mejoran"6 su vida.

14- Aprovechar las oportunidades (istiklal al furas).

15- Confidencialidad (al amana).

16- Exponer los problemas en el lugar y momento adecuados (tarh al machakil ti mauadiiha).

6 Este término lo consideraremos controvertido respecto a lo que la ayuda externa ha supuesto en el cambio de las costumbres saharauis, y cuestiona que sea lo que se les ofrece lo que realmente quieren. Abdalahi, médico de profesión, nos cuenta desde España en 2008: "yo conozco como se vive en España, trabajo aquí, y conozco como se vive allí, y prefiero vivir como un beduino, eso me haría feliz". 


\section{perifèria}

Número 10, Junio 2009

www.periferia. name

La población de los Campamentos se ha incrementado desde 1991, alejándose de la cifra de los 152.000 saharauis de 1975, gracias al periodo de tregua y a una importante natalidad. A pesar de aumentar la cantidad de proyectos y el dinero invertido no existe un reflejo en la calidad de vida de los Campamentos. ¿Dónde están 30 años de cooperación con el pueblo saharaui, sobre todo en el periodo comprendido entre 1994-2008, el de mayor inversión de proyectos de cooperación y de ayuda de emergencia? Por otro lado, los organismos internacionales siguen repartiendo la ayuda humanitaria en base a datos y censos obsoletos. La escasez de alimentos ha provocado el incremento de casos de anemia en mujeres y niños. El aumento de la pobreza es potenciado además por un reparto desigual de los recursos que introducen las familias españolas, remesas, jubilaciones, y ONGD. La frágil economía familiar lleva a las familias a vender el exceso de algunos productos de la ayuda humanitaria para poder comprar otros productos necesarios, surgiendo una economía de tipo informal o del refugio. El pueblo saharaui ha sabido reinventar la cotidianeidad y ha recibido y fomentado la ayuda para el cuerpo y la mente.

\section{El proyecto educativo y la cotidianeidad para los más desfavorecidos}

La carencia en infraestructuras (que dificultan los desplazamientos, las comunicaciones y la creación de centros médicos o educativos), de materiales y de medios humanos (falta de personal cualificado), ha provocado una desestructuración social. Los Campamentos se han organizado gracias a la voluntad nacional y al esfuerzo, pero la imposibilidad de llevar a cabo un modelo de futuro viable en el exilio ha derivado en la falta de un Estado capaz de autogestionarse. Se han reinventado cada día y existe una resistencia al olvido, sobre todo por parte de los niños, las mujeres, los ancianos y los discapacitados, ya sea desde la asistencia internacional como por sus propias iniciativas comerciales, empresariales y culturales, para recordarnos que son un pueblo vivo. 


\section{perifèria}

Número 10, Junio 2009

www. periferia. name

La atención a los discapacitados obliga que no se haga una división absoluta entre los distintos grados de discapacidad. Los pacientes/alumnos se mezclan y comparten el sistema de recursos provenientes de la ayuda internacional. Los maestros habitualmente son los que unen estas dos dimensiones a través del cuidado y la formación. Los discapacitados, y más aún si son mujeres, ancianos o niños, son grupos de riesgo de exclusión, grupos desfavorecidos con problemas de inserción, afectividad, comprensión y empatía a nivel social y familiar. Es la mujer quien asume esta responsabilidad porque le viene dado desde la propia sociedad las tareas del cuidado y del hogar.

Antes de abrir la escuela los niños ciegos no tenían ninguna oportunidad, estaban en casa todo el tiempo o perdidos por la wilaya. Los niños vienen al centro como salvajes, y les enseñamos a comportarse, a vestirse, a asearse. Se les enseña a que son iguales que cualquiera ${ }^{7}$.

\section{La educación y el mercado laboral}

Hasta 1973 la enseñanza era propiamente beduina y coránica mientras que en las ciudades colonizadas por España se imponían los estudios de la metrópoli. Este modelo de escuela colonial había legado una enseñanza para los hijos de militares y funcionarios saharauis que excluía a las familias más humildes y que rompía con la tradición, lo que fomentaba las protestas contra el colonialismo.

A partir del proceso revolucionario, se inició una campaña de escolarización y alfabetización centrada en los jóvenes. En 1976 se crearon las escuelas del 9 de Junio y el 12 de Octubre (que al principio fue una escuela militar). La construcción y Equipamiento de estas construcciones las lleva a cabo principalmente el ACNUR y ONGD que utilizan recursos de la ayuda descentralizada. Los Países amigos han ayudado esto años a la formación de bachilleres y universitarios. Los jóvenes retornados pasan por el servicio militar y hacen el juramento de lealtad a la defensa y fidelidad a la patria y a los mártires.

\footnotetext{
${ }^{7}$ Castro, director de la Escuela de Discapacitados de Smara en el año 2003.
} 


\section{perifèria}

Número 10, Junio 2009

\section{www.periferia.name}

A la enseñanza se incorpora también la escuela coránica ${ }^{8}$, donde se practica la lectura y escritura del Corán y que también incluye el "trabajo" en la casa y para la familia (tareas del hogar, ganado, cosechas) como parte del aprendizaje. Antes se enseñaba en la jaima y ahora se enseña en la mezquita, donde además se interpreta y se debate. La enseñanza no es obligatoria ni tiene plan de estudios, pero existe un gran interés por parte de los padres de que los hijos asistan. El maestro, designado a través de generaciones a una misma familia, tiene en especias o favores su sueldo.

La enseñanza religiosa aparece como una alternativa. Se enseña en escuelas que dependen del Ministerio de Justicia y Asuntos Religiosos ${ }^{9}$. Aún no hay una coordinación entre los ministerios de Educación y Justicia para regularizar las dos enseñanzas como complementarias.

La enseñanza desde el II Congreso de 1974 de la RASD, es obligatoria y gratuita en los Campamentos, y se deben matricular todos los niños a partir de los 6 años. Entre el 76 y el 84 sólo hay una escuela de primaria por wilaya, donde cursan 1 ㅇy 20 grado, y dos escuelas nacionales ( 9 de Junio y 12 de Octubre) que están fuera de las wilayas y donde terminan el grado.

En los primeros años del refugio se premiaba a los mejores de la clase con un mes de vacaciones en un País Amigo, lo que se transforma en el año 1991 en el Programa de Vacaciones en Paz del que se benefician muchos más niños durante los meses de verano y cuyos objetivos son:

\footnotetext{
${ }^{8}$ Depende del Ministerio de Asuntos religiosos.

${ }^{9}$ Creado en 1979, se encarga de elaborar leyes desde 1996, y ha podido crear tribunales, el supremo y el consejo superior de justicia. Gracias a la UNMS tienen un proyecto para reciclarse en Argelia siempre y cuando haya un 50\% de hombres y de mujeres. En el 2004 se rechazó por parte del Parlamento el Proyecto de Ley Económica. Es un proyecto muy interesante en el que los comerciantes piden que se les tome en cuenta y que conecta lo que es la normatividad y legalidad con el sistema productivo y que puede tener implicaciones interesantes a nivel de las escuelas formativas. Se pretende crear una Unión de Comerciantes que paguen impuestos pero que a cambio se les faciliten servicios y transporte de mercancías.
} 


\section{perifèria}

Número 10, Junio 2009

www. periferia.name

- lograr que vivan nuevas experiencias fuera de los campos de refugiados

- que puedan conocer nuevas culturas, un nuevo idioma, y nuevas costumbres

- y que el niño pueda ser atendido médicamente.

La escuela es parte del proceso de socialización y adquisición de valores de los niños y jóvenes, es el lugar donde se preparan las futuras generaciones para la libertad, el futuro y la igualdad en la ideología del Frente Polisario, como proyecto político internacional, desplazando a la tradición (al poder de las familias o tribus). A pesar de que la R.A.S.D. (República Árabe Saharaui Democrática) se enorgullece de que existe una casi totalidad de alfabetización, algunos trabajadores hablan de un 58\% de analfabetismo, principalmente entre las mujeres debido a sus responsabilidades en el ámbito de lo privado, y entre los jóvenes porque necesitan ganar dinero.

\section{Aspectos críticos socio-educativos}

1. Estudios en el Extranjero ${ }^{10}$ :

- Cambios socioculturales y añoranza de la familia.

- Problemas de integración al retornar a la familia y a la sociedad, que derivan en problemáticas intergeneracionales y culturales.

- Déficit en los resultados por falta de recursos.

- Falta de trabajo en sus propias especialidades cuando retornan. Otra alternativa es quedarse al margen del escaso mundo laboral o emigrar en busca de trabajo, pues el trabajo de los Campamentos les parece denigrante o insuficiente para mantener a sus familias. Además, las ONGD no recuperan a toda esta población válida.

- La Juventud ha pasado de ser promotora y constructora de un país en el refugio, a la depresión e impotencia ante la situación política. La

\footnotetext{
10 La Dirección de estudiantes en el extranjero se compone del Ministro, un gabinete y direcciones generales con correspondencias con los departamentos a nivel de las wilayas y las dairas, además de 10 responsables de educación infantil.
} 


\section{perifèria}

Número 10, Junio 2009

www. periferia. name

Juventud se encuentra ante la escasez de recursos, la incertidumbre, la falta de optimismo y la ansiedad.

- Los que trabajan por cuenta propia tienen mayor consideración porque ganan más que los retornados y los que trabajan en las instituciones.

- Algunos jóvenes deciden llevar una carrera militar, de la que poco provecho pueden sacar en un mercado laboral.

2. La mujer y el acceso al trabajo y a la formación

- Los problemas de lejanía y transporte limitan su acceso al trabajo y a los procesos formativos en los Ministerios. Además, deben cumplir con sus responsabilidades domésticas y del cuidado. Esto dificulta que se cumpla la Ley de Igualdad de Oportunidades y desanima todos sus esfuerzos para luchar en favor de la igualdad y los derechos.

- La mujer se ha unido en cooperativas como instrumento para sustituir su falta de tiempo y su falta de posibilidades, así unen sus esfuerzos.

3. La consideración de los jóvenes en las instituciones

- Los jóvenes han participado en todo el proceso revolucionario y ahora la Intifada.

- Los jóvenes carecen de atención, no se atiende a su conocimiento teórico o práctico, como por ejemplo a los artistas, porque todos los esfuerzos han ido enfocados hacia una política basada en cubrir primeras necesidades. Los artistas desde el año 2004, han provocado respuestas alternativas ante el conflicto desde sus modos de expresión.

- El movimiento migratorio supone una vía de ingresos para los jóvenes y sus familias con el que subsistir y crear negocios.

- La falta de expectativas de empleo provoca fracaso escolar y el abandono de los estudios.

- Los que emigran son mayormente hombres jóvenes, las mujeres se van con los maridos o bien se quedan en los Campamentos. Los 


\section{perifèria}

Número 10, Junio 2009

www.periferia. name

inconvenientes de la emigración son tales como la convalidación de títulos en Europa o conseguir ahorros para enviar en las remesas. Con la crisis del 2008, las familias reagrupadas en Europa se vuelven a fragmentar y sólo queda el hombre, teniendo que volver las mujeres a sus países de origen con los hijos para reducir gastos.

\section{I nstituciones, educación y mercado laboral}

Existe un gran vacío en el ámbito de la regulación legal educativa pero el Ministerio de Cooperación procura gestionarlo.

El Ministerio de la Función Pública controla, conecta y coordina todos los ministerios. Su misión es gestionar los recursos humanos, planificar, regular estructuras y determinar funciones. Los ministerios son conscientes de que la gente no quiere trabajar en ellos porque no se gana suficiente. La mujer además tiene como obstáculo para acceder a los puestos directivos:

1. que teme al fracaso (si un hombre fracasa no tiene tanta repercusión).

2. y que no confía en sí misma y no tiene autoestima en ella misma.

De los 14 miembros del gobierno sólo 2 son mujeres, y que de los 52 miembros del Parlamento sólo 12 son mujeres.

La Secretaria del Estado para Asuntos Públicos y de Empleo se fundó en 1990, y pasa de pertenecer del Ministerio del Interior al Primer Ministro. Su objetivo es emplear a quienes han culminado sus estudios.

La UGTSario se fundó en la clandestinidad durante los últimos años de la colonia española y es la única institución con carácter sindical saharaui. Sus objetivos son la mejora y la creación de trabajo, mejorar las condiciones económicas, mejorar el nivel profesional de los trabajadores y resolver los problemas de los trabajadores.

El Ministerio de Educación dice que la enseñanza, la literatura y el arte son los tres pilares de la cultura saharaui. En 1979 se publica el primer Plan de Estudios propiamente saharaui, hasta 1996 en que el aumento acelerado de los niños provoca la escasez de recursos. Como solución se envía a la mayoría de los niños 


\section{perifèria}

Número 10, Junio 2009

www. periferia. name

que finalizan la primaria a estudiar a Argelia.

Este Ministerio asume la enseñanza de todos los jóvenes desde la guardería hasta los estudios universitarios. Se encarga de su transporte, manutención y comunicación con la familia, etc. Por eso tiene dos departamentos: el de los estudiantes en el interior y el de los estudiantes en el exterior. Mientras el alumno está matriculado en las listas del ministerio, este está obligado a seguir todos los aspectos de su escolarización, a garantizar el transporte para los que estudian y los problemas sanitarios.

La UJ Sario ${ }^{11}$ realiza trabajos de movilización política en los Campamentos y en el exterior, y tareas a nivel formativo, cultural y de sensibilización. La UJ Sario trabaja con la juventud, los estudiantes, los pioneros o infancia, la mujer joven o los adolescentes sin estudios.

Trabajamos con una juventud que no tiene esperanza. Muchas veces se añaden problemas familiares a su aprendizaje porque no nos encontramos con un verdadero apoyo para que vayan al colegio, bien por ignorancia de las familias sobre la importancia de la escuela o bien porque el estudiante no tiene interés o no encuentra alicientes para ir. A veces nos encontramos con una falta de comunicación entre padres e hijos ${ }^{12}$.

Los chicos que no siguen formándose pueden caer en la delincuencia. La UJ Sario intenta remediar esta situación fomentando la animación, la formación, la construcción de centros y talleres, favoreciendo encuentro entre jóvenes, informando y dando conferencias, y fortaleciendo programas de continuidad con cooperantes. La UJ Sario promueve el estudio y la formación, para lo cual amplia el concepto de juventud entre los 15 y los 45 años, aunque saben que mucho antes la juventud te la quitan las responsabilidades.

\footnotetext{
${ }^{11}$ La UJ Sario realiza congresos, programas y leyes. Lo componen representantes: 1 por wilaya más el consejo de la wilaya, 1 por daira más el consejo de la daira, y representantes de alumnos que han estudiado en países extranjeros, territorios ocupados, militares e instituciones de Rabuni. La UJ Sario fue miembro del Movimiento de la Juventud Africana 1974, Unión de la Juventud Árabe 1975, Estudiantes Panafricanos 1975, Unión General de la Juventud de la ONU 1978, Unión Mundial de Estudiantes 1980, Unión Mundial de la Juventud Demócrata 1981.

12 Musa, empleado de la UJ Sario en el año 2007.
} 


\section{perifèria}

Número 10, Junio 2009

www. periferia. name

La UNMS aparece como una organización independiente y autorizada para definir los derechos de la mujer saharaui a través del trabajo y coordinar con el resto de mujeres cualquier aspecto de la sociedad.

\section{La escuela como centro de formación personal y profesional}

La escuela es un reflejo fiel de lo que ha sido la historia saharaui en los años de refugio. Primero se vivió una ausencia de profesorado masculino en las escuelas debido a que los hombres estaban en el frente. En estos años eran las mujeres las que enseñaban a sus hijos en las jaimas. En segundo lugar, las dificultades materiales y de infraestructuras han dificultado la realización y programación de los niveles educativos con calidad y eficacia, disminuyendo el nivel educativo y dificultando el acceso a estudios en el extranjero más exigentes. Y tercero, la educación es un reflejo de las enseñanzas recibidas en el extranjero desde países como Cuba, Libia, Argelia, etc. además de la influencia de los proyectos y personas de la cooperación.

Los retornados saharauis, principalmente los cubanos, son testimonio de un período que introduce nuevas formas de educación, disciplina, y una nueva manera de ver el mundo, además del idioma castellano, que dota de riqueza a los Campamentos.

Actualmente, el nuevo éxodo de profesionales hacia el extranjero ha supuesto una pérdida en la calidad de la enseñanza. De los que se quedan, encontramos licenciados que trabajan dando clases en primaria, lo cual supone la infravaloración de sus capacidades, además tener la sensación de haber perdido el tiempo estudiando.

Las mujeres están más interesadas en aprender, mientras que los hombres están más ocupados en otros menesteres, como el comercio, por eso los niños ven más futuro en buscarse la vida comerciando que estudiando.

Otro de los campos necesarios a la hora de revisar el ámbito educativo de los Campamentos es el empleo, el tiempo para el ocio $u$ otras alternativas culturales. La educación tiene también carencias en el sentido de que no ocupa ni potencia todos los ámbitos de desarrollo culturales, de modo que no tenemos una escuela de 


\section{perifèria}

Número 10, Junio 2009

www. periferia. name

deporte, de idiomas, de poesía, bibliotecas o centros culturales gestionados por la propia población.

La ausencia de profesionales ha permitido que se incorporen a la plantilla de maestros muchas personas que no tienen la formación suficiente y de especialidades que nada tienen que ver con lo que se enseña. Otros han estudiado una carrera pero ni siquiera se habían planteado la enseñanza. Sin embargo, aunque no todos tienen vocación, sí que tienen la voluntad de educar y proteger a su pueblo. No a todos los profesores les gusta dar clase, pero muchos han encontrado un aliciente para estar en los Campamentos y han encontrado nuevas motivaciones y retos. Todo esto es bueno para los profesores, los niños y los padres, porque hay trabajo, porque aprenden y lo complementan con el Corán y el saber beduino. A su reducido sueldo unen otras actividades como el comercio y así no verse forzados a emigrar.

Para evitar la huida de capital social, se incentiva a algunos profesores y se les asciende de puesto, lo cual provoca la pérdida de un buen profesional que acaba en los despachos. Otra forma de incentivar es ofrecer más dinero, cosa que se hace desde el 2002 y que nos lleva a la situación paradójica de que es el director quién menos cobra. También se ofrecen incentivos en especie (diploma, horas, etc.) como reconocimiento a su trabajo.

El curso escolar consta de períodos de 3 meses entre los cuales hay 15 días de descanso. Se hacen exámenes parciales cada mes y uno al final de cada trimestre. A esta nota se añade la de clase en cuanto a la participación y trabajos escritos. A los mejores estudiantes se les hace una fiesta y a los que no les va tan bien se procura averiguar por qué han fallado. También hay gente que repite: "el límite para repetir es de una vez en $1^{\circ} \circ, 2^{\circ}$, y $3^{\circ} \circ$, y dos veces en $4 ㅇ, 5$, y 60 , y si se suspende te pasan de nivel." ${ }^{13}$ El horario de la escuela tradicional es de 8.30 a 13 y de 15 a 18. Y el de la escuela coránica es de 6 a 7.30 y de 17.30 a 21.

\footnotetext{
13 Director de la Madrasa de Farsia (Smara) en los Campamentos de refugiados en el año 2006.
} 


\section{perifèria}

Número 10, Junio 2009

www.periferia. name

Los profesores se reúnen semanalmente y semestralmente por cada nivel, entre una y cuatro horas el lunes por la tarde, cuando no hay clase, para resolver cuestiones relacionadas con la escuela.

Las escuelas y el Ministerio de Educación llevan un control exhaustivo de los alumnos, de sus expedientes, tanto en los Campamentos como fuera de ellos. Ello resulta útil cuando se buscan profesores para las escuelas.

En el caso concreto de Smara, cada daira tiene su escuela, hay 8 escuelas que funcionan desde 1986. Una de ellas, la que comparten la daira de Farsia y Schederia tiene más de 800 niños, 29 maestros, 24 profesores en árabe y 5 en castellano. El programa y los libros de texto vienen de Argelia, pero a partir de 1995 en Argel decidieron cambiar el programa de estudios cada año, haciendo imposible mantener el coste del cambio anual de libros.

Los directores de la escuela llevan un registro de los materiales y de los niños. El trabajo del director no es el de impartir clase, sino el de hacer los programas educativos para niños y maestros, los programas de dirección y las reuniones. Realiza el registro de asistencia de los niños, los informes sobre el curso, los programas mensuales y observar la evolución en el estudio. El director debe cumplir el programa del Ministerio. La UNMS, la UGTSARIO y la UJSARIO actúan como apoyo en los colegios. El inspector cada seis meses participa en la clase, ve el contenido de la clase, los libros, y posteriormente se reúne con el director para establecer nuevas líneas de actuación.

Mientras que los profesores de las escuelas coránicas se forman en los propios Campamentos o en países árabes, los profesores de la escuela tradicional se forman en países occidentales o en Argelia. Algunos se quejan de que "no han tenido ninguna generación completa formada en los Campamentos, con la ideología, la religión, etc. propia de aquí"14.

\footnotetext{
${ }^{14}$ Director para estudiantes en el extranjero del Ministerio de Educación en el año 2007.
} 


\section{perifèria}

Número 10, Junio 2009

www. periferia. name

Es preferible que los estudiantes se formen en el extranjero a que vengan extranjeros a enseñar aquí porque buscamos la independencia y una cultura saharaui propia ${ }^{15}$.

El alcalde de la daira de Smara coordina todos los trabajos pero el $88 \%$ de los profesores son mujeres así como el $85 \%$ del consejo, ya que los hombres están en el ejército, en la zona liberada o comerciando. Para la Ministra de Cultura los hombres huyen de las responsabilidades, lo cual permite que la mujer siga formándose y decidiendo. Sin embargo, existe para ellas cierta dificultad en el acceso a la formación y a los puestos de responsabilidad, las obligaciones domésticas y familiares a través de la realización de tareas del cuidado y del hogar, obligaciones que unidas a los valores sociales estigmatizadores las limitan en el horario, la falta de oportunidades. Finalmente, la lejanía de sus jaimas también supone un obstáculo para sus pretensiones.

$\begin{array}{ll}1 \text { MATEMÁTICAS } & \text { 6HISTORIA, LITERATURA Y POESÍA } \\ 2 \text { LECTURA } & \text { 7 DICTADO } \\ 3 \text { ESCRITURA } & \text { 8ESPAÑOL } \\ \text { 4 DESCRIPCIÓN } & 9 \text { GRAMÁTICA } \\ 5 \text { EDUCACIÓN AL ISLAM } & 10 \text { ESTUDIO DEL MEDIO }\end{array}$

\begin{tabular}{llllll|lll} 
& \multicolumn{3}{c}{ MAÑANA } & \multicolumn{3}{c}{ TARDE } \\
& & & & & & \\
SABADO & 1 & 2 & 3 & 4 & 2 & 6 \\
DOMINGO & 1 & 2 & 5 & 4 & 2 & 1 & 3 \\
LUNES & 1 & 2 & 5 & 4 & - & - & - \\
MARTES & 1 & 2 & 5 & 3 & 1 & 2 & 6 \\
MIÉRCOLES & 1 & 2 & 3 & 6 & 2 & 1 & 9 \\
JUEVES & 1 & 2 & 5 & 3 & - & - & -
\end{tabular}

Tabla 1. Modelo de asignaturas para los grados Primero y Segundo

\footnotetext{
15 Director de personal del Ministerio de Educación en el año 2007.
} 


\section{perifèria}

Número 10, Junio 2009

www. periferia. name

$\begin{array}{ll}1 \text { MATEMÁTICAS } & \text { 6 HISTORIA, LITERATURA Y POESÍA } \\ 2 \text { LECTURA } & \text { 7DICTADO } \\ 3 \text { ESCRITURA } & \text { 8ESPAÑOL } \\ \text { 4 DESCRIPCIÓN } & 9 \text { GRAMÁTICA } \\ 5 \text { EDUCACIÓN AL ISLAM } & 10 \text { ESTUDIO DEL MEDIO }\end{array}$

5 EDUCACIÓN AL ISLAM 10ESTUDIO DEL MEDIO

\begin{tabular}{lllll|lll} 
& \multicolumn{3}{c}{ MAÑANA } & \multicolumn{3}{c}{ TARDE } \\
SABADO & 1 & 2 & 3 & 4 & 1 & 2 & 6 \\
DOMINGO & 1 & 2 & 5 & 4 & 2 & 1 & 3 \\
LUNES & 1 & 2 & 5 & 4 & - & - & - \\
MARTES & 1 & 2 & 5 & 3 & 1 & 2 & 6 \\
MIÉRCOLES & 1 & 2 & 3 & 6 & 2 & 1 & 9 \\
JUEVES & 1 & 2 & 5 & 3 & - & - & -
\end{tabular}

Tabla 2. Modelo de asignaturas para el Tercer Curso.

$\begin{array}{ll}\text { 1 MATEMÁTICAS } & \text { 6HISTORIA, LITERATURA Y POESÍA } \\ \text { 2 LECTURA } & \text { 7DICTADO } \\ \text { 3 ESCRITURA } & \text { 8ESPAÑOL } \\ \text { 4(o) DESCRIPCIÓN ORAL } & 9 \text { GRAMÁTICA } \\ \text { 4(e) DESCRIPCIÓN ESCRITA } & 10 \text { ESTUDIO DEL MEDIO } \\ \text { 5EDUCACIÓN AL ISLAM } & \end{array}$

\begin{tabular}{lccccccc}
\multicolumn{5}{c}{ MAÑANA } & \multicolumn{3}{c}{ TARDE } \\
SABADO & 1 & 8 & 2 & 9 & 1 & 7 & 5 \\
DOMINGO & 1 & 8 & 2 & 9 & 1 & $4(0)$ & 10 \\
LUNES & 1 & 8 & 2 & 9 & - & - & - \\
MARTES & 1 & 8 & 2 & 9 & 1 & $4(0)$ & 5 \\
MIÉRCOLES & 1 & 8 & 2 & 9 & 1 & $4(\mathrm{e})$ & 10 \\
JUEVES & 1 & 8 & $714(\mathrm{e})$ & 1 & - & - & -
\end{tabular}

Tabla 3. Modelo de asignaturas para los grados Cuarto, Quinto y Sexto.

\section{Causas del fracaso escolar y perspectivas}

Existe una falta de continuidad del curso escolar porque:

- La familia prefiere que su hijo esté con ellos en la jaima, que aprenda el Corán y que pase largos períodos de tiempo en el bedia, donde no hay 


\section{perifèria}

Número 10, Junio 2009

www. periferia. name

formación reglada.

- Faltan recursos.

- Disminuye el nivel del profesorado por la emigración de los universitarios al extranjero.

- Todo ello, junto a la ausencia de salidas laborales para los que terminan los estudios en las escuelas de Formación Profesional y los universitarios retornados, provoca apatía en el profesorado y hace que la escuela sea una alternativa de segunda clase.

- En los Campamentos se vive con decepción las posibilidades y los recursos que se les ofrece desde el exterior.

- Las diferencias económicas entre las familias les obliga a marcarse unos objetivos distintos (estudiar o trabajar). Estas diferencias económicas nacen del desigual acceso a los recursos e ingresos que tienen las familias (ayudas de las familias españolas, pensiones de la época colonial, contratos con ONGD, ayudas de familiares emigrantes, etc.).

- Falta de reciclaje del profesorado en la adquisición de nuevos conocimientos. Por otro lado, la mayor parte de los profesores que hay actualmente no tienen formación pedagógica ni estudios suficientes.

- Son necesarios profesionales capaces de motivar y de motivarse, que se les tenga en consideración, y que tanto padres como alumnos valoren la formación académica.

- Se han de diseñar programas curriculares y no curriculares detallados, con claros objetivos, contenidos y metodología. Y procurar que las enseñanzas dentro de los Campamentos puedan tener una aplicación dentro o fuera de los mismos.

\section{Demandas formativas}

- Necesidad de una formación completa desde su propia idiosincrasia, con una apuesta contundente por el fomento del empleo, con la finalidad de evitar la 


\section{perifèria}

Número 10, Junio 2009

www. periferia. name

huida de profesionales. Para ello hay que encontrar productos competitivos en el mercado y proyectos viables.

- Solicitar un reconocimiento monetario a las ONGD para valorar el propio trabajo.

- Formar a la gente del bedia en otras disciplinas, muchos niños no comienzan las clases hasta que tienen 5 o 10 años.

- Procurar el reconocimiento de los diplomas saharauis en el extranjero, principalmente los de la formación profesional.

- El gobierno pretende introducirse y organizar el mercado para no adquirir vicios del capitalismo occidental ni tener problemas con los demás países, aunque es el propio mercado saharaui el que emergió sin ningún tipo de programación.

- El Ministerio del Interior y el Ministerio de Salud establecen comisiones para seguir los precios de los productos en las wilayas.

- El Ministerio de Comercio y el Ministerio de Cooperación obligan a vender al mismo precio a los comerciantes pero sin necesidad de policía ni reglamentos. Si aumentan los precios se buscan soluciones. Este ministerio también controla el Fondo Nacional, un capital que subvenciona tiendas y a los ministerios de Salud y Educación.

- Los territorios liberados tienen recursos: plantas medicinales, ganados, artesanía, que pueden consumir los propios saharauis si se produce con calidad, e incluso de exportarse fuera como manufactura o como objeto artístico. En la elaboración de los objetos y prácticas tradicionales se ocuparían parte de la población y se conservarían costumbres, además de generar empleo.

\section{Centros de formación, producción y servicios}

Una vez finalizada la primaria en 60 grado, los alumnos pasan al 12 de Octubre para realizar estudios medios. Posteriormente terminarán los estudios superiores en 


\section{perifèria}

Número 10, Junio 2009

www. periferia. name

el extranjero. Como alternativa a los estudios universitarios pueden realizar Formación Profesional. Otros tipos de centros de estudio son los de producción y servicios, nacidos de las manos de ONGD como Hegoa en Smara. Estos centros trabajan diferentes aspectos prácticos para la vida cotidiana. Se estructuran en una secretaría general, un responsable de equipamiento, un inspector ${ }^{16}$ de pedagogía, un asistente pedagógico y un asesor de idioma castellano.

La escuela de Olof Palme se inaugura en 1989 en el Aaiún por una organización femenina y socialista sueca con el fin de formar a mujeres saharauis. Los periodos de formación en Olof Palme son de 2 años en costura, tejido y dibujo técnico y de 3 años para administración.

\begin{tabular}{|c|c|c|}
\hline Olof Palme & Curso 2008 & Observaciones \\
\hline Tejido & 10 & \multirow{6}{*}{$\begin{array}{l}\text { Compuesta por } 6 \text { Aulas, Biblioteca, Sala de } \\
\text { actividades y reuniones, Recepción, } \\
\text { Guardería, Comedor, Almacenes. }\end{array}$} \\
\hline Textura & 10 & \\
\hline Costura & 10 & \\
\hline Administración & 10 y $2 \circ$ & \\
\hline Dibujo técnico 2004 & 10 & \\
\hline Educadoras & 10 & \\
\hline
\end{tabular}

Tabla 4. Materias de la escuela Olof Palme.

La escuela de Gazuani tiene dos cursos en muchas de sus especialidades pero debido a la falta de profesores y la falta de demanda de estos trabajos se hace el primer curso un año uno y el segundo curso el año siguiente.

\footnotetext{
16 El Inspector atiende a los alumnos en el tiempo extraescolar y de descanso, tiene en mente las circunstancias de cada uno y del refugio con el fin de recibir una buena educación.
} 


\section{perifèria}

Número 10, Junio 2009

www. periferia. name

\begin{tabular}{|c|c|c|}
\hline $\begin{array}{c}\text { GAZUANI -70 } \\
\text { alumnos }\end{array}$ & $\begin{array}{c}\text { Cursos } \\
2008\end{array}$ & Observaciones \\
\hline Electricidad doméstica & 20 & \multirow{6}{*}{$\begin{array}{l}\text { Hay chicos y chicas a jornada } \\
\text { partida y en régimen de } \\
\text { internado. } \\
\text { Su mayor problema es la lejanía } \\
\text { respecto de todas las wilayas. }\end{array}$} \\
\hline Informática & 10 y 20 & \\
\hline Mecánica & 20 & \\
\hline Carpintería & 20 & \\
\hline Soldadura & 20 & \\
\hline Construcción & 20 & \\
\hline
\end{tabular}

Tabla 4. Materias de la escuela Gazuani.

El Centro de Formación de EL LUALI se creó en 1984 con ayuda de la experiencia argelina. Hacía formación de administrativos, escritoras de máquinas, mecánicos de coches, electricidad de autos, soldadura y electricidad doméstica. En 1986 se añade carpintería y mantenimiento de coches. Actualmente el centro no está en condiciones para dar clases.

El Centro de Formación de HEGOA en Smara, además de los estudios antes mencionados, quiere apoyar estudios y trabajos en electrónica, panadería, pastelería, lavandería, peluquería, imprenta, locutorio, fotografía, relojería y clínica dental.

Los proyectos de cooperación pueden hacer diferentes tipos de reflexiones:

1. ¿Qué tipo de productos y servicios se requieren?, ¿qué es lo que la gente quiere, necesita o puede hacer con los recursos disponibles? y ¿qué posibilidades hay de sostenerlo en el tiempo y autogestionarlo?.

2. Estudio de mercado. 


\section{perifèria}

Número 10, Junio 2009

www.periferia.name

3. Atención a los Grupos de Exclusión: mujeres, ancianos, niños y discapacitados.

4. Ha de verse la Formación Profesional como unos estudios completos y de calidad, interesantes tanto a nivel práctico como teórico.

\section{Los límites para la mujer en el ámbito educativo y social}

La mujer ha pasado de estar relegada de lo público a hacerse un hueco ya desde la revolución y desde la lucha, gracias principalmente a la (UNMS) ${ }^{17}$. Subyugada y abocada a ser una buena madre y esposa, a las tareas del cuidado y a quedarse en el espacio de lo privado, la mujer es socialmente estigmatizada si infringe estos hábitos sociales. Pero su ansia de igualdad, de aprendizaje, y de alcance de los derechos para la mujer y sus nuevas ideas, han permitido que la mujer se haya convertido en una fuerza social que emerge a nivel político para disminuir las desigualdades generadas desde posiciones sexistas, y así ir conquistando lo público y parcelas de poder.

La mujer es un valor cultural porque, como el hombre, transmite los valores culturales de su pueblo, y su transmisión se produce en el seno familiar como en las escuelas. Por otro lado, la cultura saharaui se ha politizado tanto que van quedando en segundo plano los temas sociales y culturales cotidianos y tradicionales, sustituyéndose por una historia bélica y del refugio, que podemos observar muy bien en canciones y poesías. La sociedad saharaui está de acuerdo en que la cultura es el principal elemento de lucha y reivindicación.

La poesía apoya esta recuperación cultural e identitaria. La poesía representa el sentimiento y las vivencias, las transformaciones de conceptos como tierra, individuo, colectivo, en definitiva, de la identidad saharaui. La emigración, la diáspora y el éxodo, el medio ecológico, las costumbres, la economía y su modo de vida, se muestran a través de la poesía del combate, del sentimiento y del conflicto.

\footnotetext{
17 www.arso.org/UNMS-1.htm.
} 


\section{perifèria}

Número 10, Junio 2009

www.periferia. name

La poesía saharaui es el medio culto por excelencia de comunicación de la tradición y el saber a través de la oralidad y la memoria. Los poetas son una clase social muy respetada, son quienes mantienen la conciencia colectiva y la identidad del pueblo.

Tipología de las poesías:

1. La poesía del Combate (El Fahjar) es la poesía del orgullo que se canta antes y durante el combate. Su forma musical corresponde al Fahgu, al que se añade como acompañamiento la guitarra de 3-4 ó de 6-12 cuerdas. Su origen es africano y el cantante tiene mucho poder respecto a lo que dice.

2. La poesía Sentimental (El Kasel) trata sobre la mujer, la belleza y el amor. Dentro de esta categoría podemos encontrar lo que se llaman Canciones de Sombra, que son poesías que se recitan despacio, sin mucho ritmo ni sonido.

3. Y finalmente la poesía del Conflicto (Chemt) que trata de amores, de la sociedad, del hospedaje, etc.

Para Badi Mohamed Salem "la poesía es como un huerto en el que siembras y cosechas, pero antes se ha tenido que cuidar, trabajar la tierra, protegerlo del viento, eliminar malas hierbas... Para ser poeta hay que nacer, pero además cultivarse porque se debe conocer y saber tratar todos los géneros". Badi nos habla de la importancia de la crítica poética: "hay poetas que tienen mucha prisa, publican su poesía antes de exponerla a la crítica. Yo, someto mi poesía al análisis y a la crítica, así saldrá una buena poesía. (...) No puede haber un poeta que sea el mejor de todos y el mejor para siempre, hay, eso sí, buenos momentos poéticos. El crítico es el médico de la poesía, conviene consultarlo antes de publicar"18.

La recuperación de la historia, la costumbre y los derechos lingüísticos a través de la memoria, la oralidad y los documentos escritos, debería ser potenciada vivamente dentro de la lucha política y de su especificidad cultural, considerada también patrimonio de la humanidad. La recuperación y el mantenimiento de la

\footnotetext{
18 Poeta nacido en Tiris en 1937 es considerado el decano de la poesía saharui y mantiene contactos y nutre a las nuevas generaciones de poetas como la Generación de la Amistad (grupo de poetas que han compartido experiencias, el exilio, el estudio y el trabajo en los campamentos y con otros países). www.generacionamistadsaharaui.com
} 


\section{perifèria}

Número 10, Junio 2009

www.periferia. name

cultura en la memoria no tiene porqué significar su práctica cotidiana cuando son elementos que se quieren transformar o eliminar, pero sí deben ser conscientes las nuevas generaciones de lo que fueron las cosas y cómo se están transformando y por qué.

La generación de poetas modernos es la Generación de la Amistad, una generación de poetas saharauis que han estudiado principalmente en Cuba y que desarrollan su actividad intelectual en otros países, principalmente España, que editan libros de poesía propios como un modo más de lucha por su independencia.

Se reconocen saharauis y son un soplo de aire fresco en términos culturales en los Campamentos. Sus vidas no han sido como la de aquellos que no han salido nunca del refugio, tienen otras inquietudes añadidas por sus circunstancias $y$, otra manera de querer expresarlas y de pensarlas. No necesariamente lo cultural, a diferencia de lo que normalmente tendemos a pensar, es algo que se enfrenta, sino que más bien, en su diversidad se complementa y produce una realidad más hermosa y menos lineal que la que algunos pretendieran.

\section{Bibliografía}

Bonelli Rubio, J. (1944). El problema de la colonización, CSIC.

Caro Baroja, J. (1990). Estudios saharianos. Madrid: Júcar.

Contreras, J. (1991). “Los grupos domésticos: estrategias de producción y reproducción", en VV.AA. Antropología de los pueblos de España. Madrid: Taurus.

Criado, R. (1977). Pasión y muerte de un sueño colonial. Ruedo Ibérico.

D.Smith, A. (2000). Nacionalismo y modernidad. Madrid: ISTMO.

El Corán (1999). Barcelona: Herder.

Hernández Moreno, A. (1989). Economía y sociedad del Sáhara Occidental. Universidad de Murcia.

Juliano, D. (1999). La causa saharaui y las mujeres. Barcelona: ICARIA. 